\title{
Letter to the Editor regarding the article "Effectiveness of ultrasonography in the postoperative follow-up of pediatric patients undergoing ureteroscopic stone manipulation"
}

\author{
Abdulkadir Tepeler • Tolga Akman • \\ Murat Binbay $\cdot$ Ahmet Yaser Muslumanoglu
}

Accepted: 7 December 2011/Published online: 23 December 2011

(C) Springer-Verlag 2011

This is an important study demonstrating the radiation safety and effectiveness of the ultrasonography (US), adjacent to plain film, in the postoperative follow-up of children with ureteral calculi treated with ureteroscopy (URS) [1]. US is the most popular, effective and X-ray free imaging modality used for children in the diagnosis of follow-up period. In addition, it provides the threedimensional visualization of the urinary tract. Doppler US is another safety and highly specific method in the diagnosis of residual ureteral stones after extracorporeal shock wave lithotripsy (ESWL) [2]. The usage of doppler US in the follow-up of children after the URS procedure may increase the sensitivity and specificity of the US.

In addition of the cumulative or deterministic effects of the radiation which are commonly known, the stochastic effects of ionizing radiation, which are not dose-dependent and do not have a threshold, may lead to genetic mutations and cancer. Mean radiation doses per diagnostic interventions are $0.05 \mathrm{mSv}$ for anteroposterior and lateral abdomen graph (equal to 2.5 chest $\mathrm{X}$-ray radiation dose), $0.33 \mathrm{mSv}$ for fluoroscopic cystogram (equal to 16 chests X-ray dose) and $5 \mathrm{mSv}$ for abdomen CT (equal to 250 chests X-ray dose) for a 5-year-old child [3]. It is underlined that a single abdomen CT in a 1-year-old child would cause in one CT related death per 550 scans [4]. The URS is generally performed under fluoroscopic guidance that may

A. Tepeler $(\bowtie) \cdot$ T. Akman

Department of Urology, Faculty of Medicine,

Bezmialem Vakif University, Adnan Menderes Bulvar1,

Fatih, Istanbul, Turkey

e-mail: akadirtepeler@yahoo.com

M. Binbay · A. Y. Muslumanoglu Department of Urology, Haseki Teaching and Research Hospital, Istanbul, Turkey lead to the radiation exposure. Krupp et al. [5] underlined that the delivered radiation from fluoroscopy devices during URS is not in the level to be underestimated. Although the imaging guidance modality used for URS in the study is not described [1], the selection of guidance method during the endoscopic treatment of pediatric patients is very important as well as the imaging methods used for followup.

In conclusion, pediatric urologists should consider the deleterious effects of radiation exposure and choose the appropriate imaging method for the diagnosis, treatment and follow-up of urinary stone disease in children, who are more sensitive to the effects of radiation.

\section{References}

1. Resorlu B, Kara C, Resorlu EB, Unsal A (2011) Effectiveness of ultrasonography in the postoperative follow-up of pediatric patients undergoing ureteroscopic stone manipulation. Pediatr Surg Int 27:1337-1341

2. Ciftci H, Cece H, Dusak A, Savas M, Verit A, Yeni E (2010) Study of the ureterovesical jet flow by means of duplex Doppler ultrasonography in patients with residual ureteral stone after extracorporeal shock wave lithotripsy. Urol Res 38:47-50

3. Rice HE, Frush DP, Farmer D, Waldhausen JH, APSA Education Committee (2007) Review of radiation risks from computed tomography: essentials for the pediatric surgeon. J Pediatr Surg 42(4):603-607

4. Stratton KL, Pope JC IV, Adams MC et al (2010) Implications of ionizing radiation in the pediatric urology patient. J Urol 183:2137-2142

5. Krupp N, Bowman R, Tenggardjaja C, Jellison F, Hill B, Ebrahimi K, Smith J, Farley D, Baldwin DD (2010) Fluoroscopic organ and tissue-specific radiation exposure by sex and body mass index during ureteroscopy. J Endourol 24:1067-1072 